involved in its functioning. However, significant differences of opinion have been detected on issues of importance, such as security arrangements and clinical original papers

responsibility. The impact of these differences on clinical practice merits further attention. A multi-disciplinary approach to practice is felt to be of paramount importance. This would entail not only an appropriate training common to all disciplines, but adequate support from senior colleagues, team building and renewal of core values, aiming, as suggested by Tyrer (1998), at a common philosophy of care.

It is not known to what extent the differences in opinions observed within the different disciplines from the $\mathrm{CIS}$ are unique, or whether these would occur in another multi-disciplinary team setting. This is outside the scope of this paper, but could be the subject of a further study.

It is plausible that the attitudes and views of the CIS professionals may have a bearing on the ability of the service to operate effectively. Similar surveys, perhaps conducted on a regular basis, might serve as a means of allowing the views of professionals to be explored and shared. This may in turn have a beneficial affect on the $\mathrm{CIS}$, helping to ensure its efficient and cohesive operation.

We have not attempted to correlate the attitudes of $\mathrm{CIS}$ professionals with patient outcome measures such as patient satisfaction. Keeble et al (1997) showed high levels of satisfaction of patients and significant others with the service provided by the CIS.

The issues raised here are of importance to existing crisis services and to those that may be planning to establish a CIS

\section{Acknowledgements}

We would like to thank Jane Simpson for her help in the initial stages of the project, and Drs Butler, Ikkos, Margerison and Ratna and Professor Winter for their helpful comments on the manuscript. We would also like to thank Jill Terry and her colleagues at the Edgware Community Hospital library for their kind help.

\section{References}

AGUILERA, D. \& MESSIK, J. (1982) Crisis RATNA, L. (1978) The Practice of Intervention. Theory and Methodology Psychiatric Crisis Intervention. St (4th edn). Missouri, USA: Mosby. $\quad$ Albans, Hertfordshire: Napsbury BALDWIN B. A. (1978) A paradigm for Hospital League of Friends. the classification of emotional crises: implications for crisis intervention. SZMUKLER, G. I. (1987) The place of crisis intervention in psychiatry. Australian and New Zealand Journal of Psychiatry, 21, 24-34.

\section{$48,538-551$.}

HOBBS, M. (1984) Crisis intervention in theory and practice: a selective review. British Journal of Medical Psychology, 57, 23-34.

TYRER, P. (1998) Cost-effective or profligate community psychiatry? British Journal of Psychiatry, 172, 1-3.

KEEBLE, P., METCALFE, C., RILEY,T., et al (1997) Cross purposes. Health Services Journal, 107, 28-29.

WINTER, D. A., SHIVAKUMAR, H., BROWN, R. J., et al (1987) Explorations of a crisis intervention service. British Journal of Psychiatry, $151,232-239$

Fernando Lazaro Specialist Registrar, Addenbrooke's Hospital, Cambridge, Elena Kulinskaya Senior Statistician, University of Hertfordshire, ${ }^{*}$ Robert Tobiansky Consultant Old Age Psychiatrist and Honorary Senior Lecturer, Department of Old Age Psychiatry, Colindale Hospital, Colindale Avenue, London NW9 5HG; tel: 02089522381

Psychiatric Bulletin (2001), 25,98-101

SEAN WHYTE AND ANDREW BLEWETT

\title{
Deliberate self-harm
}

\section{The impact of a specialist DSH team on assessment quality}

\section{AIMS AND METHOD}

A repetition after 5 years of a prospective case note audit, looking at the impact of a recently established deliberate self-harm (DSH) assessment team on the quality of DSH assessments at Kettering general hospital.
RESULTS

A specialist DSH team achieved improvement in the quality of psychiatric assessments for the majority of patients who harmed themselves. Assessments of mental state by accident and emergency ( $A \& E$ ) and medical staff before referral to the psychiatric team remain problematic.

\section{CLINICAL IMPLICATIONS}

Setting up a specialist team to assess patients who harm themselves can improve the quality of the psychiatric care they receive, but emphasis must still be placed on an adequate assess ment of mental state by medical and nursing staff in $A$ \& $E$ and on medical wards.
Presentations to accident and emergency (A \& E) departments after deliberate self-harm (DSH) are common (over 150000 annually in the UK) and becoming more so (House et al, 1998). These patients suffer high rates of psychiatric disorder (Morgan et al, 1975) and are 100 times more likely than the average member of the population to commit suicide in the year after presentation (Greer \& Bagley, 1971). Although patient assess- ments do not reliably predict the risk of future DSH (Hawton \& Fagg, 1995), they can identify patients with treatable mental disorder (House et al, 1998). The Department of Health recommends that every patient have a 'specialist psychosocial assessment' before discharge from hospital (Department of Health and Social Security, 1984). Assessments by A \& E staff alone have been shown to omit important items such as continuing 
suicidal ideation (Black \& Creed, 1988; O'Dwyer et al, 1991; Ebbage et al, 1994).

At present, the majority of screening assessments are carried out by junior doctors on emergency rotas (House et al, 1998), although suitably trained nurses and social workers can perform assessments of similar quality (Newson-Smith \& Hirsch, 1979; Catalan et al, 1980). In October 1998, a team of part-time specialist nurses supported by a psychiatrist was set up at Kettering general hospital. This team now sees the majority of patients: specifically, those presenting to $A$ \& E between 5.00 p.m. and $1.00 \mathrm{a} . \mathrm{m}$. and those admitted to a general hospital bed. We examined quality variables linked to DSH psychiatric assessment by repeating an audit conducted in 1994 (Gordon \& Blewett, 1995), when most assessments were by on-call trainee psychiatrists.

\section{Method}

Both the 1994 audit and this 1999 reaudit used the same reported criteria (Black \& Creed, 1988). We set out to examine 50 consecutive sets of notes for DSH patients presenting to $A \&$ E from March 1999, aged 16 years or over. Cases were identified using the A \& E computerised patient database. Four patients' case notes were untraceable; the 50 included patients were therefore drawn from the first 54 patients presenting after 1 March
1999. To avoid bias, staff in A \& E and on the medical admissions unit, and psychiatric staff performing assessments, were not told when data were to be collected, although all were aware that an audit was planned.

The samples were analysed in checklist fashion according to 58 predetermined criteria, for example: "Had the A \& E senior house officer (SHO) made any note, however brief, of mental state?" To ensure comparability, the 1994 data were reanalysed using the 1999 criteria. Data analysis was completed by S.W. A sub-sample was checked for agreement by A.B., with complete concurrence. The patients concerned were almost all unknown to S.W., and in most cases he did not know which staff member had performed the assessment. Measures of statistical significance were all based on a simple comparison of independent proportions, analogous to McNemar's test for paired proportions (Mould, 1998).

\section{Results}

In the 1999 audit, 25 of the 50 study patients were admitted to a general hospital bed and seven were eventually admitted to a psychiatric bed (Fig. 1). Thirtynine were assessed by trained psychiatric personnel: 15 in $A$ \& $E$ and 24 in a general hospital bed. One patient discharged himself after being admitted to a medical bed

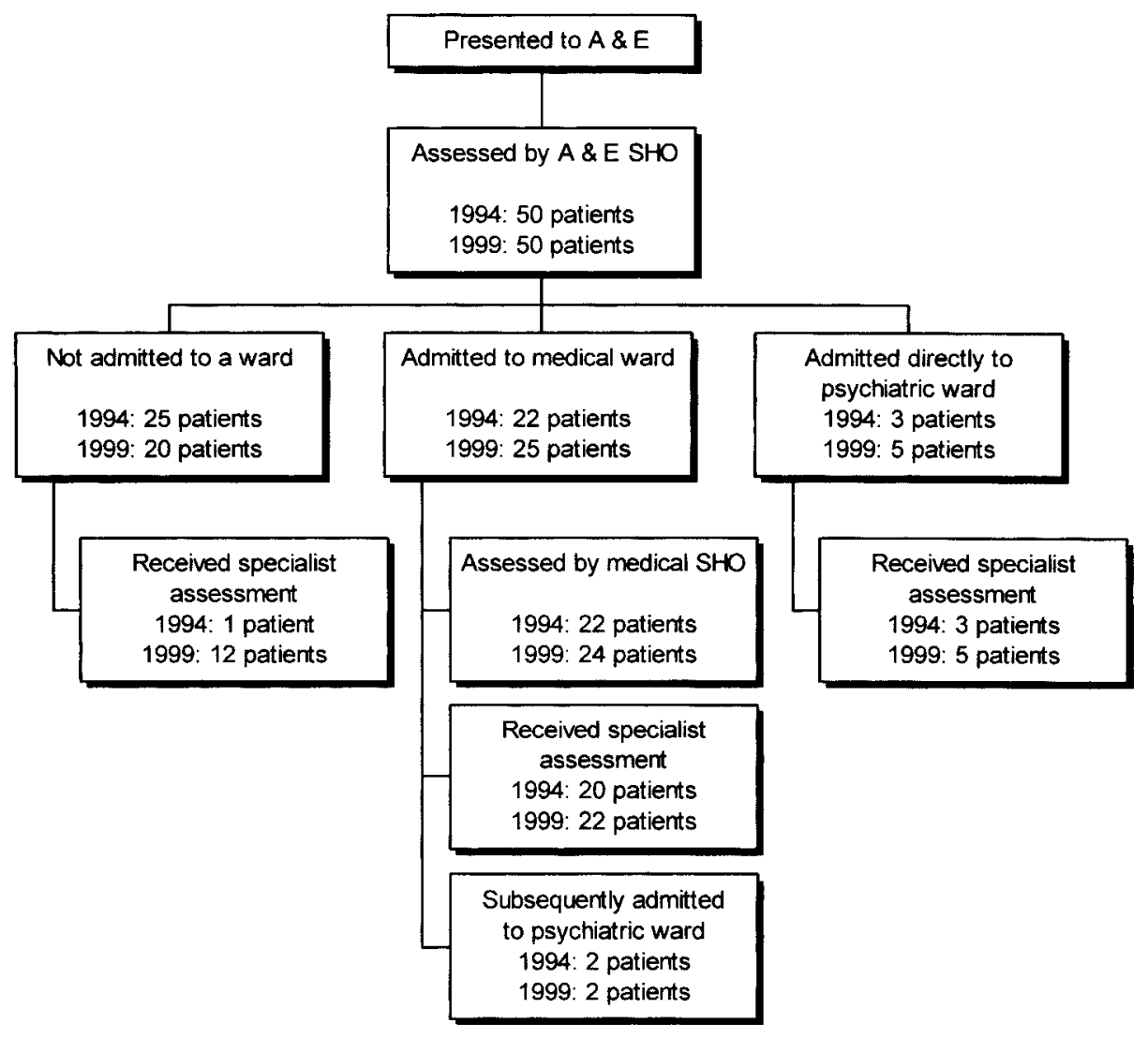

Fig. 1 Assessment and admission patterns for patients presenting to the accident and emergency (A \& E) department. One of the three patients admitted directly to a psychiatric ward in 1994 was a readmission of a patient who had discharged himself without permission. One of the patients admitted to a medical ward in 1999 discharged himself before assessment by the medical senior house officer (SHO) 
Table 1. Quality of specialist deliberate self-harm (DSH) and accident and emergency (A \& E) mental state assessments

original papers

Assessments on which parameter was documented ( $n(\%))$

\begin{tabular}{|c|c|c|c|}
\hline Parameter documented on assessment & \multicolumn{2}{|c|}{ Assessments on which parameter was documented ( $n(\%))$} & Test for difference \\
\hline \multicolumn{4}{|l|}{ Specialist DSH assessments } \\
\hline Act of self-harm & $11(46)$ & $39(100)$ & $P<0.001$ \\
\hline Precipitating factors & $17(71)$ & 37 (95) & $P<0.01$ \\
\hline Whether alcohol was used & $3(13)$ & $38(97)$ & $P<0.001$ \\
\hline Social circumstances & $14(58)$ & $39(100)$ & $P<0.001$ \\
\hline Past psychiatric history & $9(38)$ & $39(100)$ & $P<0.001$ \\
\hline Family psychiatric history & $5(21)$ & $36(92)$ & $P<0.001$ \\
\hline Patient's mental state & $14(58)$ & $38(97)$ & $P<0.001$ \\
\hline Ongoing suicide risk & $15(63)$ & $38(97)$ & $P<0.001$ \\
\hline \multicolumn{4}{|l|}{ A \& E assessments } \\
\hline Act of self-harm & $50(100)$ & $50(100)$ & $P=\mathrm{NS}$ \\
\hline Whether alcohol was used & $50(100)$ & $17 \quad(34)$ & $P<0.001^{1}$ \\
\hline Past psychiatric history & $14 \quad(28)$ & $36(72)$ & $P<0.001$ \\
\hline Patient's mental state & $31 \quad(62)$ & $40 \quad(80)$ & $P<0.05$ \\
\hline Ongoing suicide risk & $24(48)$ & $21 \quad(42)$ & $P=N S$ \\
\hline Total number of assessments & 50 & 50 & \\
\hline
\end{tabular}

with a prior non-specialist A \& E assessment and no further psychiatric evaluation. The projected annual DSH presentation rate rose from 521 in 1994 to 852 in 1999 Patient characteristics in both samples were similar for age group and method of self-harm and consistent with published studies (Charlton et al, 1993; McLoone \& Crombie, 1996). There is a continuing predominance of analgesic poisoning as a method of self-harm and a low female to male ratio: 1:1 in 1994 and just under $2: 1$ in 1999.

The proportion of patients receiving a specialist assessment before discharge from hospital rose from 24/ $50(48 \%)$ in 1994 to 39/50 (78\%) in 1999. The change in service structure was also reflected in the type of specialist assessment. In 1994, 17 (71\%) of the 24 specialist assessments were completed by on-call SHOs and the remainder by community nurses. In 1999, 34/39 $(87 \%)$ were completed by a member of the DSH team and the remainder by on-call SHOs. The proportion of patients seen by a mental health worker who were referred on to a statutory sector agency other than the general practitioner fell significantly, from 16/24 (67\%) in 1994 to $12 / 39$ (31\%) in 1999 ( $P<0.01$ for difference). This is contrary to the suggestion that non-medical staff performing DSH assessments recommend psychiatric follow-up more often than doctors do (Newson-Smith, 1988).

Bed utilisation did not significantly alter. The medical admission rate increased marginally, from $22 / 50$ (44\%) in 1994 to $25 / 50(50 \%)$ in 1999 ( $P>0.5, N S)$, and eventual new admission to a psychiatric bed rose from 4/50 (8\%) to $7 / 50(14 \%)(P>0.1, N S)$. In contrast, the change in rate of eventual psychiatric admission following specialist assessment was unremarkable: 4/24 (17\%) in 1994 compared to $7 / 39$ (18\%) in 1999 ( $P>0.5$, NS).

The most consistent and significant change was of improved quality of specialist assessments in the second audit (Table 1). The quality of assessments by $A \& E$ and medical ward staff either remained poor or declined slightly. Data for assessments by medical ward staff not shown.

\section{Comments}

This paper replicates earlier published findings that a trained team of nurses can perform high-quality assessments, and shows a substantial and significant improvement in assessment quality after such a team was set up in Kettering. There was no evidence that this improvement generalises to non-specialist staff working in $A \& E$ and medical assessment units.

There are weaknesses intrinsic to the design of this audit. The two case series are relatively small, and we were not systematically blinded to the identity of patients or assessors. Failure to identify patients using the information system in A \& E was a risk, although the 1994 sample was hand-checked and previous experience suggested that data entry and extraction by predetermined codes minimised errors.

The data presented are an accurate reflection of the original 58 criteria. The 14 criteria not described here include additional demographic variables. Further items are presented in a condensed form; for example, "was there a documented plan of action?" is a conflation of "was there an immediate management plan?", "was there a follow-up plan?" and "was there a decision to admit?". 
We considered that improvement in quality of documented assessments was attributable to the development of a specialist team with dedicated staff and time. The team's cohesion and positive ethos, with a strong emphasis on training, monitoring of standards and mutual support, is experienced as very important.

There is still a paucity of firm evidence guiding interventions aimed at reducing repetition of DSH or suicide following it. This audit focused on the broader question of assessment quality, in the reasonable expectation that if treatable disorders are identified patients will be more likely to access appropriate help. Despite improvements, the current service arrangement in Kettering does not yet ensure that every patient has an adequate psychosocial assessment, which begs a question about whether its clinical activities should be expanded. A major concern is that consistent and satisfactory basic mental health evaluation and management of DSH patients by non-specialist staff have not yet been achieved.

\section{Acknowledgements}

We thank Dr Kate Gordon, who carried out the original audit in 1994, and Ceri-Anne Ashby and Beverley Isherwood of the Clinical Effectiveness Department, who assisted in identifying patients and locating case notes.

\section{References}

BLACK, D. \& CREED, E. (1988) Assessment of self-poisoning patients by psychiatrists and
CATALAN, J., MARSACK, P., HAWTON, K. E., et al (1980) Comparison of doctors and nurses in the assessment of deliberate self-poisoning patients.

Psychological Medicine, 10 483-491.

CHARLTON, J., KELLY, S., DUNNEL, K. et al (1993) Suicide deaths in England and Wales. Trends in factors associated with suicide deaths. PopulationTrends, 71, 34-42.

DEPARTMENT OF HEALTH AND SOCIAL SECURITY (1984) The management of deliberate self-harm. HN, 84, 25 .

EBBAGE, J., FARR, C., SKINNER, D.V., et al (1994) The psychosocial assessment of patients discharged from accident and emergency departments after deliberate selfpoisoning. Journal of the Royal Society of Medicine, 87, 515-516.

GORDON, C. \& BLEWETT, A. (1995)

Deliberate self-harm: service development in Kettering. Psychiatric Bulletin, 19, 475-477.

GREER, S. \& BAGLEY, C. (1971) Effect of psychiatric intervention in attempted suicide: a controlled study. British Medical Journal, 1, 310-312.

HAWTON, K. \& FAGG, J. (1995) The performance of the Edinburgh predictive scales in patients in Oxford. Archives of Suicide Research, 1 261-272.
HOUSE, A., OWENS, D. \& PATCHETT, L. (1998) Deliberate self-harm. Effective Health Care, 4, 2-9.

MCLOONE, P. \& CROMBIE, I. (1996) Hospitalisation for deliberate selfpoisoning in Scotland from 1981 to 1993: trends in rates and types of drugs used. British Journal of Psychiatry, 169, $81-85$

MORGAN, H. G., BURNS C. C. POCOCK, H., et al (1975) Deliberate self-harm: clinical and socio-economic characteristics of 368 patients. British Journal of Psychiatry, 127, 564-574.

MOULD, R. F. (1998) Introductory Medical Statistics. Bristol: Institute of Physics Publishing.

NEWSON-SMITH, J G. B. (1988) The use of social workers as alternatives to psychiatrists in assessing parasuicide. InThe Suicide Syndrome (eds R. Farmer $\&$ S. Hirsch). London: Croome Helm.

— \& HIRSCH S. R. (1979) A comparison of social workers and psychiatrists in evaluating parasuicide. British Journal of Psychiatry, 134, 335-342.

O'DWYER, F. G., DALTON, A. \& PEARCE, J. B. (1991) Adolescent selfharm patients: audit of assessment in an accident and emergency department. British Medical Journal, $303,629-630$

Sean Whyte Senior House Officer, Oxford Regional Psychiatric Rotation,

*Andrew Blewett Consultant Psychiatrist, The Reddliffe Centre for Community Psychiatry, 51 Hatton Park Road, Wellingborough NN8 5AH

\section{M. FOREMAN}

\section{General practitioners and child and adolescent psychiatry: awareness and training of the new commissioners}

\section{AIMS AND METHOD}

General practitioners' (GPs')

informed awareness of the various medical specialities underpins their ability to manage and commission services for their patients. Three questions, relevant to GP practice, to test awareness of child and adolescent mental health services (CHMHS) were developed and sent to $238 \mathrm{GP}$ principals in North Staffordshire.

\author{
One hundred and seventy-six \\ responded. \\ RESULTS \\ Forty-seven per cent had no under- \\ graduate training in CAMHS and 93\% \\ had negligible postgraduate experi- \\ ence. Only $27 \%$ thought they saw \\ CAMHS cases frequently. Sixty-four \\ per cent usually referred those they \\ saw. Relevant expertise made \\ referral to CAMHS less likely, as
}

\begin{abstract}
did membership of the Royal College of General Practitioners. Seventythree per cent wanted more training, but only $7 \%$ thought training easy to obtain.

\section{CLINICAL IMPLICATIONS}

These findings confirm the need for child and adolescent psychiatrists to become directly involved in the commissioning of their services and GP training.
\end{abstract}

Child and adolescent mental health services (CAMHS) are inadequately developed over much of the country (Health Advisory Service, 1995), so effective commissioning will be vital if CAMHS are to thrive in the new NHS. The latest health service reorganisation (Department of Health, 1997) has made primary care groups or trusts - which 